\title{
Public Health Measures to Prevent the Adverse Impact of Air Pollution on Health
}

\author{
Saurabh Ram Bihari Lal Shrivastava*, Prateek Saurabh Shrivastava and Jegadeesh Ramasamy
}

Department of Community Medicine, Shri Sathya Sai Medical College and Research Institute, Kancheepuram, India

\begin{abstract}
Air pollution refers to the presence of substances in the surrounding atmosphere, in such concentrations that they start interfering with human health/comfort, or is injurious to vegetation/animals, or plays a significant role in environmental degradation. The recent estimates released by the World Health Organization have raised serious concerns, and thus air pollution has been now acknowledged as the world's largest single environmental health risk. Acknowledging the impact of air pollution on different dimensions of health, it is of prime importance to reduce extent of air pollution so that lives of millions can be saved in future. In conclusion, considering the number of deaths attributed to air pollution and its associated short and long-term impact on human health and environment, it is the need of the hour to take a concerted effort to reduce the magnitude of air pollution worldwide.
\end{abstract}

Keywords: Air pollution; Health; Environment

\section{Introduction}

Air pollution refers to the presence of substances (like gases, mixture of gases and particulate matter) in the surrounding atmosphere, which are generated by the activities of humans, in such concentrations that they start interfering with human health/comfort, or is injurious to vegetation/animals, or plays a significant role in environmental degradation [1].

\section{Impact on Health}

The recent estimates released by the World Health Organization has raised serious concerns as in the year 2012 alone, almost 7 million people died (4.3 million - household air pollution +3.7 million ambient air pollution), owing to their exposure to air pollution, with maximum deaths being reported in the Western Pacific and South East Asian regions [2]. These estimates are alarming as the number of deaths has almost doubled in contrast to the past estimates, and thus air pollution has been now acknowledged as the world's largest single environmental health risk [2,3]. Furthermore, on a global scale around 1600 cities spread across 91 nations are reporting higher air pollution levels [4].

\section{Household (Indoor) Air Pollution}

Around 3 billion people worldwide, most of whom are from low/ middle income nations, are still using biomass (wood, animal dung and crop waste) and coal for different purposes [5]. These procedures have resulted in extremely high levels of household air pollutants like particulate matter and other poisonous gases [5]. In-fact, premature deaths have been reported both in children (pneumonia), and in adults (stroke/myocardial ischemia/chronic obstructive pulmonary disease/ lung cancer) because of the household air pollutants [1,5-8].

\section{Ambient (outdoor) Air Pollution}

Out of the 3.7 million deaths attributed to exposure to ambient air pollution in the year 2012, almost $88 \%$ of the casualties were again from the low/middle income nations [9]. Different air pollutants like particulate matter (asthma exacerbations, and asthma hospitalizations), ozone (plays a major role in the pathophysiology of asthma), nitrogen and sulfur dioxide (associated with development of broncho constriction, impaired lung function, lung inflammation and respiratory tract irritation) have been associated with variable adverse effects to both human (increased medial expenditure, sickness absenteeism, disability, impact on quality of life, etc.) and their surrounding environment [1,912].

\section{Recommended Public Health Measures}

Acknowledging the impact of air pollution on different dimensions of health, it is of prime importance to reduce extent of air pollution so that lives of millions can be saved in future $[2,9,11]$. Although, effective policies and strategies are existing, nevertheless, their implementation on a large scale in a uniform manner is lagging [2]. Thus, it is the responsibility of the public health authorities of individual cities to adopt and implement local measures to improve the air quality $[5,9]$. In-fact, definitive evidence is available to suggest that cities like Copenhagen and Bogotà, have significantly improved the quality of air by encouraging urban public transport, and activities like walking or cycling among the residents [13].

A wide range of measures such as ensuring that houses are energy efficient [13] developing a mechanism to maintain household energy database [5] communicating standardized exposure limits to air pollutants to various nations [9], well-planned development of cities [9], good quality public transport options [13], appropriate measures to handle air pollutants (in industries, for vehicles, during power generation, waste disposal, etc.) [1,14], facilitating operation of power plants that use clean and renewable fuels [13], enabling development of safer roads [3], formulating holistic legislative measures [1], providing

*Corresponding author: Dr. Saurabh Ram Bihari Lal Shrivastava, Department of Community Medicine, 3rd floor, Shri Sathya Sai Medical College and Research Institute, Ammapettai village, Thiruporur - Guduvancherry Main Road, Sembakkam Post, Kancheepuram-603108, Tamil Nadu, India, Tel: +919884227224; E-mail: drshrishri2008@gmail.com

Received April 16, 2015; Accepted May 30, 2015; Published June 06, 2015

Citation: Shrivastava SR, Shrivastava PS, Ramasamy J (2015) Public Health Measures to Prevent the Adverse Impact of Air Pollution on Health. Biol Med S3: 001. doi: 10.4172/0974-8369.S3-001

Copyright: ( 2015 Shrivastava SR, et al. This is an open-access article distributed under the terms of the Creative Commons Attribution License, which permits unrestricted use, distribution, and reproduction in any medium, provided the original author and source are credited. 
Citation: Shrivastava SR, Shrivastava PS, Ramasamy J (2015) Public Health Measures to Prevent the Adverse Impact of Air Pollution on Health. Biol Med S3: 001. doi: 10.4172/0974-8369.S3-001

Page 2 of 2

support to the nations which are not yet engaged in systematic air quality monitoring $[3,14]$, enhancing international collaboration by developing a global platform for monitoring air quality [2-4], extending support to various nations to strengthen the existing efforts and to share the information on various successful approaches or other recent developments $[15,16]$ and fostering research work to establish the impact of various air pollutants on health $[5,16]$ can be implemented to reduce the aftermaths of air pollution.

\section{Conclusion}

In conclusion, considering the number of deaths attributed to air pollution and its associated short and long-term impact on human health and environment, it is the need of the hour to take a concerted effort to reduce the magnitude of air pollution worldwide.

\section{References}

1. Park K (2009) Environment and Health: Textbook of Preventive and Socia Medicine. (21stedtn), Banarsidas Bhanot Publishers, Jabalpur, India.

2. Burden of disease from the joint effects of household and ambient air pollution for 2012 (2014) World Health Organization, Geneva, Switzerland.

3. Burden of disease from ambient and household air pollution (2015) World Health Organization, Geneva, Switzerland.

4. World Health Organization (2014) Ambient (outdoor) air pollution in cities database. WHO, Geneva.

5. World Health Organization (2014) Household air pollution and health - Fact sheet $\mathrm{N}^{\circ} 292$. WHO, Geneva.
6. Makri A, Stilianakis NI (2008) Vulnerability to air pollution health effects. Int J Hyg Environ Health 211:326-36.

7. Szpiro AA, Sheppard L, Adar SD, Kaufman JD (2014) Estimating acute air pollution health effects from cohort study data. Biometrics 70:164-74.

8. Qureshi MI, Rasli AM, Awan U, Ma J, Ali G, et al. (2015) Environment and ai pollution: health services bequeath to grotesque menace. Environ Sci Pollut Res Int 22:3467-476.

9. World Health Organization (2014) Ambient (outdoor) air quality and health Fact sheet, WHO, Geneva

10. Kim JJ (2004) American Academy of Pediatrics Committee on Environmental Health (2004) Ambient air pollution: health hazards to children. Pediatrics 114:1699-1707.

11. Miraglia SG, Saldiva PH, Böhm GM (2005) An evaluation of air pollution health impacts and costs in São Paulo, Brazil. Environ Manage 35:667-676.

12. Namdeo A, Stringer C (2008) Investigating the relationship between air pollution, health and social deprivation in Leeds, UK. Environ Int 34:585-591.

13. World Health Organization (2014) Air quality deteriorating in many of the world's cities, WHO, Geneva, Switzerland.

14. Deguen S, Ségala C, Pédrono G, Mesbah M (2012)A new air quality perception scale for global assessment of air pollution health effects. Risk Anal 32:20432054.

15. Wartenberg D (2009) Some considerations for the communication of results of air pollution health effects tracking. Air Qual Atmos Health 2:207-221.

16. Thurston GD, Bekkedal MY, Roberts EM, Ito K, Pope CA 3rd, et al. (2009) Use of health information in air pollution health research: past successes and emerging needs. J Expo Sci Environ Epidemiol 19:45-58.
This article was originally published in a special issue, Human Biology and Education handled by Editor. Saurabh Ram Bihari Lal Shrivastava, Shri

Sathya Sai Medical College and Research Institute, India 